\title{
Technical and economical factors in green roof using to reduce the aircraft noise
}

\author{
Elena Korol $^{1}$, Natalia Shushunova ${ }^{1, *}$, Oksana Feoktistova $^{2}$, Tatiana Shushunova ${ }^{3}$, Oleg \\ Rubtsov ${ }^{1}$ \\ ${ }^{1}$ Moscow State University of Civil Engineering, Yaroslavskoe shosse, 26, Moscow, 129337, Russia \\ ${ }^{2}$ Moscow State Technical University of Civil Aviation, 20 Kronshtadtsky blvd, Moscow, 125993, \\ Russia \\ ${ }^{3}$ Mendeleyev University of Chemical Technology of Russia, Institute of Economics and Management, \\ Miusskaya sq., 9, 125047 Moscow, Russia
}

\begin{abstract}
The relevance of research is due increased environmental tensions associated with the noise impact of transport, including the problem of aircraft noise. The purpose of the study is the development of reduce the impact of aircraft noise on the population living near airports, and assessment of the cost-effectiveness of measures to implement measures to reduce noise interference with the device of green roof systems on residential and public buildings near aviation facilities. The predominance of green spaces, architectural forms and other elements of improvement contribute to improving the environment, quality of life, including by reducing the noise load. Based economic analysis and assessment of the noise situation use greening strucrures that improve the well-being of the local population, this particularity concerns the provision of health and psychological comfort of the population. The assessment of the ecological and economic efficiency of green roof systems has shown that the benefits of the green spaces are multifunctional, and in addition to reducing noise, they also reduced the island's effect of heat by creating a shadow, reduce the need for conditioning, reduce wind load, filter harmful emissions, improve air quality and preserve biodiversity.
\end{abstract}

\section{Introduction}

In recent years, civil aviation has been intensively developing, there are more powerful engines that are installed on more modern air assets. In our time, with the emergence of new types of aircraft and the saturation of traffic in air transport, there is the problem of reducing the impact of noise on a person, which is becoming more urgent.

Each year the national and international requirements to the acoustic and environmental situation in the airport area become tougher, as well as to the negative impact of the impact of aircraft noise on humans, animals and the environment. Increasingly, complaints are received from air personnel, engineering personnel and the public. From an economic point of view, there is a negative external effect, a negative externality, since the activities of air

\footnotetext{
* Corresponding author :nshushun@gmail.com
} 
carriers lead to a real damage to the health of third parties - the population living near airports, which incur additional costs associated with treatment that are not compensated for. Negative external effects negatively affect the economic position of the noise pollutants themselves [1-3]. In this case, the costs and damage from the activities of air carriers are literally external, since they do not affect their own costs. Air carriers tend first of all to minimize their internal costs, and they usually ignore external, external costs as a problem requiring additional costs for their solution. In theory, one of the known ways of taking into account the interests of the population is the imposition of a special tax on pollutants, equal in magnitude to the external costs, of the so-called Pigou tax. In our country, the state is interested in the health of its population and regulates the negative external effect of noise pollution by setting standards for permissible noise levels in residential, public buildings and residential buildings [Sanitary Norms SN 2.2.4 / 2.1.8.562-96 "Noise at workplaces, in residential, public buildings and on the territory of residential buildings "(approved by the decision of the State Committee for Sanitary and Epidemiological Control No. 36 of October 31, 1996)]. At the same time, at present there are no clear criteria for assessing the compatibility of airports and the requirements for protecting people from the negative impact of aviation, for example, the criteria for the admissibility of residential and social development in the aerodrome area, depending on the levels of aircraft noise on it. In addition, at present, there are no restrictions on aircraft noise in the town-planning plan for a land plot of a specific territory, and as a result, its influence is not taken into account. It also does not take into account the effect of aircraft noise when placing building objects and developing noise protection measures $[4,5]$. This violates the rights and legitimate interests of citizens.

\section{The impact of aircraft noise}

According to the latest biomedical research published in European scientific publications, the noise of over $55 \mathrm{dBA}$ adversely affects the comfort and health of more than a third of the European population [6-8]. First of all, it affects the human nervous system, promotes the development of many diseases of the cardiovascular system and other human organs, including causing sleep disturbances. Acoustic irritations gradually accumulate and lead to fatigue, irritability, drowsiness, hypertension and other more serious consequences. When exposed to strong noise exposure, people may experience various symptoms, such as ear pain, dizziness, headache, etc. There is a possibility that the changes in the work of various systems and organs can cause changes in the emotional state of workers and the population. These changes can lead to stress. Also worth noting the ongoing violation of concentration, speech impairment, manifestation of fatigue, associated with increasing energy costs $\square 9 \square$.

It was found that if the noise level is over $75 \mathrm{~dB}$, the severity of hearing can be reduced, the understanding of spoken language, continuous sound exposure leads to a slow progressive decrease in hearing sensitivity initially in the range of high tones, and then spreads to neighboring frequencies, age-related hearing loss (prebiakusis) begins at $5-7$ years earlier. At noise of $40 \ldots 70 \mathrm{dBA}$, the nervous system begins to suffer, primarily vegetative, at the values of $85 \mathrm{dBA}$ disturbances of peripheral blood circulation and changes in blood pressure are observed.

On the territory of residential buildings located near airports, the equivalent sound level for round-the-clock, intensive operation is $80 \mathrm{dBA}$ in the daytime and $78 \mathrm{dBA}$ at night. Equivalent sound levels are reduced to $77 \ldots 70 \mathrm{dBA}$ in the daytime with a distance of $4 \mathrm{~km}$ from the end of the runway and by 70-75 dBA - at night. These figures depend on the airport class. At a distance of 2 to $3 \mathrm{~km}$ perpendicular to the axis of the runway, the equivalent sound levels are reduced. In the daytime, they are 64-61 dBA, at night - 59-55 $\mathrm{dBA}$. The study of the impact of sound in the vicinity of the airports makes it possible to 
present a noisy clamor, and to analyze the propagation of noise in the terrain within a radius of $6 \mathrm{~km}$. In the aisles 4-6 km from the runway, where the take-off and approach runs are concentrated, the waiting zone, the movement of aircraft most intensively affects the noise regime of the terrain [2].

Comparison of actual sound levels in the residential area near airports with permissible sound pressure levels (Table 1) showed their excess both in daytime and at night.

Table 1. Acceptable sound pressure levels, sound levels, equivalent and maximum sound levels of penetrating noise in residential and public buildings and noise in the residential area.

\begin{tabular}{|c|c|c|c|c|c|c|c|}
\hline \multirow[t]{2}{*}{$\begin{array}{l}\text { Time of } \\
\text { day }\end{array}$} & \multicolumn{7}{|c|}{$\begin{array}{l}\text { Sound pressure levels, } \mathrm{dB} \text {, in octave bands with medium geo- } \\
\text { metric frequencies, } \mathrm{Hz}\end{array}$} \\
\hline & 31,5 & 63 & 125 & 250 & 500 & 1000 & 2000 \\
\hline $\begin{array}{l}\text { from } 7 \mathrm{am} . \\
\text { to } 23 \mathrm{pm} .\end{array}$ & 79 & 63 & 52 & 45 & 39 & 35 & 32 \\
\hline $\begin{array}{l}\text { from } 23 \mathrm{pm} \text {. } \\
\text { to } 7 \mathrm{am} .\end{array}$ & 72 & 55 & 44 & 35 & 29 & 25 & 22 \\
\hline
\end{tabular}

Since aircraft noise is somewhat specific (depends on such factors as the direction of the runways, the intensity of flights during the day and year, the flight paths, the types of aircraft, etc.) and in connection with the development of the world fleet, the growth of intensity of regional and international flights, it was necessary to solve the problem of reducing the noise regime in the vicinity of airports.

\section{Measures to reduce aircraft noise}

To reduce the sound levels in the territory or in the rooms of objects protected from noise, screens should be used that are placed between noise sources and objects to be protected from noise.

The decrease in the sound level of the screen in $\mathrm{dB}$ is determined depending on the difference in the path lengths of the sound beam $\delta$ in $m$ at the adopted screen height.

The difference in the path lengths of the sound beam $\delta$ in $\mathrm{m}$ should be determined by the formula:

$$
\begin{gathered}
\Delta=(\mathrm{a}+\mathrm{b})-\mathrm{c}, \\
\Delta=(15+20)-30=5 \mathrm{~m},
\end{gathered}
$$

where a - the shortest distance between the geometric center of the noise source and the upper edge of the screen in $\mathrm{m}, 15 \mathrm{~m}$,

$\mathrm{b}$ - the shortest distance between the calculated point and the top point of the screen in $\mathrm{m}, 20 \mathrm{~m}$;

c - the shortest distance between the geometric center of the noise source and the calculated point in $\mathrm{m}, 30 \mathrm{~m}$.

Reducing the sound level of the screen and in $\mathrm{dB}$, should be determined from the value in $\mathrm{dB}$ and the angles and with the adopted screen length.

The value of the sound level reduction $\Delta L_{\text {Ascreen }}$ in the dBA should be determined by the formula:

$$
\Delta L_{\text {Ascreen }}=\Delta L_{\text {Ascreen } \alpha}+\Lambda \text { add }
$$

where: $\Delta L_{\text {Ascreen } \alpha}$ - the smaller of the values in $\mathrm{dBA}$, 
$\Lambda$ add - correction in dBA, is determined depending on the difference in the values of and. In this case, the length of the screen should be taken to be twice the length of the noise source.

When the height of the protective screen is $10 \mathrm{~m}$ and the length is $50 \mathrm{~m}=23 \mathrm{dBA}$. Decrease in the sound level in the dBA by strips of green plantations should be taken from the calculation of where the noise comes from and what is its source. When planting strips of green plantations, close connection of the tree crowns with each other should be ensured and the space under the crowns filled to the surface of the earth by a shrub.

Strips of green plantations should be provided from the rocks of fast-growing trees and shrubs that are resistant to air conditions in cities and other settlements and grow in the appropriate climatic zone. Also, as a protection against noise, a "green" roof system can be used (Figure 1).

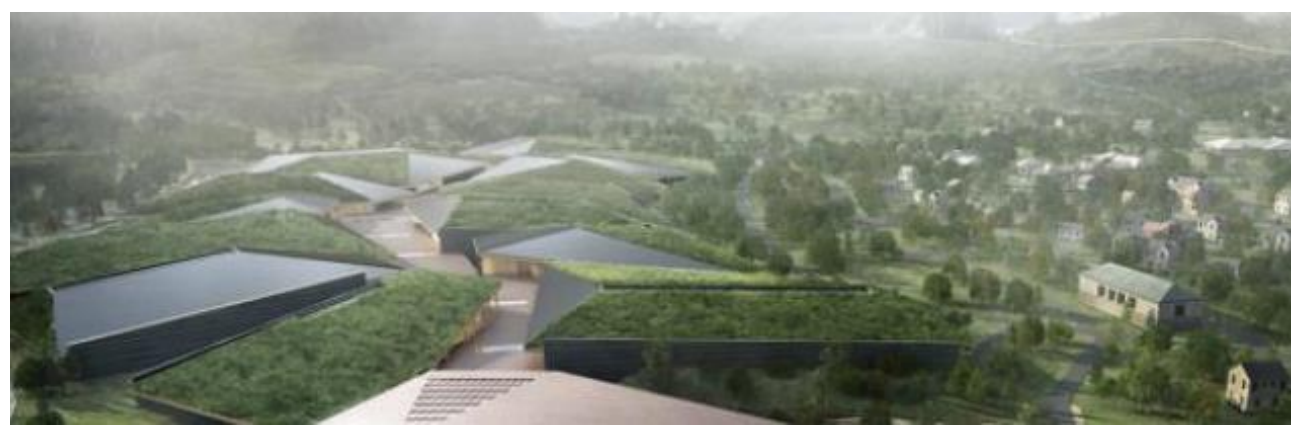

Fig. 1. Using green roof to solve the problem of reducing aircraft noise.

Vegetable eco-covers are very popular, and there are several serious reasons for this:

- Durability. A green vegetable roof with gas will serve longer than a normal roof. After all, soil and plants best protect it from negative environmental factors, as well as from weather conditions. If you properly take care of such a roof, then the life of the roof will exceed 20 years.

- Stormwater retention. This is especially true when there are heavy showers, because the sewage system often does not cope with a lot of water. Lawns and other vegetation located on the roof, are able to absorb some of the precipitation - about $27 \%$. This is an effective way to help prevent flooding. In addition, pollution of nearby rivers and reservoirs is reduced.

- High sound insulation. The garden on the roof contributes to the reduction of the noise background in the internal premises, which is also important for the inhabitants of houses located near the airfields.

- Great thermal insulation. In the house under the plant roof in the winter is warm, and in the summer heat it is cool. Therefore, the cost of heating and air conditioning is reduced. Elevated thermal engineering requirements for the roof will ensure optimal conditions for the layers of the construction of the coating [10].

- Additional space. The territory of the exploited green roof provides an additional useful area for landscape design. There can be sow the lawn, break the garden and equip the pool, the great place to relax $[11,12]$.

- Improvement of the environment from the environmental position.

- Aesthetics. The house under the green roof looks unusual and original.

\section{Results and discussion}

The authors proposed the following measures to reduce the impact of noise: 
1. When designing buildings, facilities of aviation enterprises, development of technological processes [13], in this case for the operation of aviation and ground equipment at airports, all necessary measures should be taken to reduce noise to values not exceeding permissible.

2. Implement engineering solutions aimed at reducing noise in sources; wider use of the newest low-noise aircraft, airfield vehicles and means of mechanization of maintenance; use low-noise technological processes, equipment, etc.

3. Carry out construction and planning activities that provide for the maximum possible removal of noise sources from workplaces (rational choice of locations for testing sites for engines and parking areas for aircraft in the airport territory, correct orientation of the aircraft taking into account prevailing weather conditions); more widely use the screening of noise by special devices (acoustic screens OST 54 7200482 , buildings and structures, green plantations); increase sound insulation of enclosing structures of buildings and structures (walls, windows, doors); apply such soundproofing structures as soundproofing cabins, casings; Increase the sound absorption in the path of noise propagation, especially by acoustic cladding of walls, ceilings and the device of additional sound absorption.

\section{Conclusions}

Thus, based on the assessment of the noise situation, in order to reduce noise in urban areas, measures were proposed for the introduction of improved engineering solutions aimed at reducing noise in sources and using green plantations, and also considering the possibility of using mechanization for maintenance and low-noise technological processes. The application of green building technologies in the installation of green roofs is the most effective solution, while providing high functionality in comparison with traditional types of roofs.

\section{References}

1. T.G. Feoktistova, O.G. Feoktistova, T.V. Naumova, Industrial Sanitation and Occupational Health: Proc. allowance (INFRA-M, Moscow, 2013)

2. O.G. Feoktistova, T.G. Feoktistova, Actual trends in the development of fundamental and applied sciences at the turn of the 21st century: monograph (ROS.Gos.agrar.zaoch.un.)

3. Night noise guidelines for Europe (WHO Regional Office for Europe, Copenhagen, 2009)

4. Guidance on the Balanced Approach to Aircraft Noise Management, 9829 (2008)

5. O.G. Feoktistova, I.N. Merzlikin, The Moscow State Technical University (2017)

6. European Aviation Environmental Report 10, 65-78 http://www.easa.europa.eu/eaer/references?

7. D. Schreckenberg, R. Guski, I. Schvaus, U. Moehler, R. Schuemer, Annoyance and disturbances due to traffic noise at different times a day (ZEUS, GmbH, RuhrUniversity, Moehler Partner)

8. Noise action plan London agglomeration Environmental noise (DEFRA, England, 2010)

9. Potential health risks of exposure to noise (SCENIHR, 2008)

10. O.A. Korol, Construction Materials 6, 13-15 (2015) 
11. Review of the implementation of Directive 2002/49, EC on environmental noise (Miheu, 2010)

12. S.E. Suarez, L.M. Recuero, The study of annoyance by the noise in Menorca Islands population, Instituto Universitario de Investigacion del Automovil INSIA, U. Politecnica de Madrid

13. E. Korol, P. Kagan, T. Barabanova, I. Bunkina, International Journal of Applied Engineering Research 11-3, 1691-1693 (2016) 